\title{
Space experimental studies of microgravity fluid science in China
}

\author{
HU WenRui ${ }^{1 \dagger}$, LONG Mian ${ }^{1}$, KANG ${ }^{1}{ }^{1}$, XIE JingChang ${ }^{1}$, HOU MeiYing ${ }^{2}$, ZHAO JianFu ${ }^{1}$, DUAN Li ${ }^{1}$ \\ \& WANG ShuangFeng ${ }^{1}$ \\ ${ }^{1}$ National Microgravity Laboratory, Institute of Mechanics, Chinese Academy of Sciences, Beijing 100190, China; \\ ${ }^{2}$ Beijing National Laboratory for Condensed Matter Physics, Institute of Physics, Chinese Academy of Sciences, Beijing 100190, \\ China
}

Microgravity fluid physics is an important part of microgravity sciences, which consists of simple fluids of many new systems, gas-liquid two-phase flow and heat transfer, and complex fluid mechanics. In addition to the importance of itself in sciences and applications, microgravity fluid physics closely relates to microgravity combustion, space biotechnology and space materials science, and promotes the developments of interdisciplinary fields. Many space microgravity experiments have been performed on board the recoverable satellites and space ships of China and pushed the rapid development of microgravity sciences in China. In the present paper, space experimental studies and the main results of the microgravity fluid science in China in the last 10 years or so are introduced briefly.

microgravity fluid physics, microgravity gas-liquid two-phase flow, microgravity complex fluid, microgravity combustion, space biotechnology

The technologies of rockets and satellites require the study of the fluid management problem in the storage tanks, and such problems of microgravity engineering in the microgravity environment have been studied in China during the development of space technology ${ }^{[1]}$. Studies on microgravity sciences in China were started in the late 1980s, when the scientists completed some space experiments on board the Chinese recoverable satellites by the promotion of the National HighTechnology Research Program of China. Main research subjects were the scientific experiments of materials science, in charged by the experts of the Institute of Semiconductor of the Chinese Academy of Sciences (CAS) and the Lanzhou Institute of Physics ${ }^{[2-4]}$, and experiments of space biology, in charged by the experts of life sciences in the $\mathrm{CAS}^{[5-7]}$. Some nice results were obtained, although resources of space experiments on board the recoverable satellite were relatively limited in the preliminary period.

Microgravity fluid physics is an import part of mi- crogravity sciences, and requires relatively complicated experimental facility in general, mostly the optical diagnostic instrumentations. Theoretical and experimental studies of the microgravity fluid physics on the ground were started relatively early in China ${ }^{[8]}$; the scientists of China and Japan jointly completed the microgravity experiments of the thermocapillary convection in floating half zone ${ }^{[9]}$ and drop Marangoni migration ${ }^{[10]}$ using the JAMIC drop shift in Hokkaido and the MGLAB drop shift in Toki respectively before the foundation of the Beijing Drop Tower, and the experimental results were nice. China's first space experiment of fluid physics was completed 10 years later after the initiation of one of the materials science. The experiments of Marangoni convection and thermocapillary convection in two immiscible liquid layers were performed on board the SJ-5

\footnotetext{
Received June 27, 2009; accepted August 17, 2009 doi: $10.1007 / \mathrm{s} 11434-009-0680-7$

'Corresponding author (email: wrhu@imech.ac.cn)

Supported by the Knowledge Innovation Project of the Chinese Academy of Sciences (Grant No. KJCX2-L08), and National Natural Science Foundation of China (Grant Nos. 10872202, 10672171 and 30730032)
} 
scientific satellite in 1997. The flow pattern experiment of liquid-gas two-phase flow during a long microgravity period was firstly completed on board the MIR Space Station of Russia in 1999. The experiment of drop Marangoni migration was done successfully on board the space ship Shen Zhou (SZ-4) in 2004. The experiment of bubbles migrations and interaction and the principle experiment of new type bio-reactor were fulfilled on board a Chinese recoverable satellite in 2005. The un-recoverable capsule of SJ-8 scientific experimental satellite was used as a payload entitled to perform 9 microgravity experiments ${ }^{[11]}$, of which 6 experiments were related to microgravity fluid science. Good academic results were obtained from these space experiments.

\section{Experiments on Marangoni convection and thermocapillary convection in two immiscible liquid layers}

The buoyancy convection is suspended, and the Marangoni convection (in which the applied temperature difference is perpendicular to the free surface) and the thermocapillary convection driven by the non-uniformity of surface tension (in which the applied temperature difference or surface tension gradient introduced by other sources is parallel to the free surface), become the main natural convections in the microgravity environment ${ }^{[12]}$. Three typical configurations are used for the research of the thermocapillary convection, that is, the model of a floating half zone, the model of a co-axial cylindrical vessel, and the liquid layer model in a rectangular cavity. Keeping a liquid layer in the microgravity environment is very difficult. The thermocapillary convection in a liquid layer has not been successfully completed $^{[13]}$; the Marangoni convection in a single liquid layer is not arranged yet in space experiment. The thermocapillary convection in three immiscible liquid layers was studied to simulate the encapsulated floating zone during crystal growth, and scientific results of space experiments were obtained ${ }^{[14,15]}$.

Numerical research was done before our space experiment ${ }^{[16]}$, which was completed for the Marangoni convection (with applied temperature difference between the upper and lower boundaries) and thermocapillary convection (with applied temperature differences between the left and right boundaries) on board the SJ-5 un-recoverable satellite in 1997. The inner volumes of the two experimental facilities were $48 \mathrm{~mm} \times 20 \mathrm{~mm} \times 32$ $\mathrm{mm}$ and $35 \mathrm{~mm} \times 20 \mathrm{~mm} \times 32 \mathrm{~mm}$ respectively ${ }^{[17]}$. FC-70 and paraffin were adopted as the mediums of the two liquid layers. The melting point of paraffin was adjusted to be in liquid state during the experiment in space and in solid state during and before the launch. Two liquid layers were formed clearly after the paraffin was melted, and the system of the two liquid layers was stable ${ }^{[18]}$. However, bubble appeared near the right side boundary of the FC-70 liquid layer for the Maragoni convection and near the cold boundary of paraffin liquid layer for the thermocapillary convection when the paraffin was melted. Flow fields of the two liquid layers with bubble were calculated by the numerical simulation method as shown in the right columns of Figures 1 and 2, and the related experimental results obtained by PIV measurement were shown in the left columns of Figures 1 and 2 for comparison. The temperature difference was $23^{\circ} \mathrm{C}$ between upper and lower boundaries for the Maragoni convection with a bubble in the lower and lower corner, and $41{ }^{\circ} \mathrm{C}$ between left and right boundaries for the thermocapillary convection with a bubble in the upper and left corner, and both results were comparable. Basic features of the convections in two liquid layer systems with bubbles were explained by the results of numerical simulations ${ }^{[19]}$.

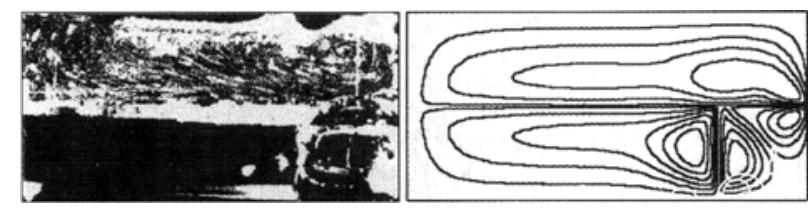

Figure 1 Comparison of space experimental results (left) and numerical simulation results (right) for Maragoni convection in two liquid layer systems.

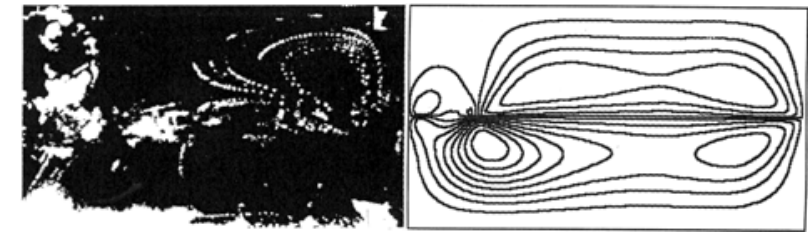

Figure 2 Comparison of space experimental results (left) and numerical simulation results (right) for thermocapillary convection in two liquid layer systems.

\section{Experiments on two-phase gas-liquid flow}

There exists large difference between densities of two phases in two-phase gas-liquid systems, resulting in 
strong gravity influences on the flow, such as stratification due to buoyancy force, velocity slip between phases, and so on. In a microgravity environment, these effects can be weakened and even fully restrained, and thus the flow structure in pipes or flow patterns will show some simplification. The major flow patterns in microgravity are reported as bubble, slug and annular flows ${ }^{[20]}$. There are, however, some transitional regions due to the fact that the classification of flow patterns mainly depends on eyes, which is not objective but subjective. Then, some transitional flows such as bubble-slug and slugannular flows are also reported in the literature. They sometimes even appear as main flow patterns in flow pattern map.

Collaborating with the researchers from the Keldysh Research Center of Russia, we carried out the first experimental study on two-phase flow patterns in a long-term, steady microgravity environment aboard the Russian Space Station Mir in August 1999, which is the only opportunity to have data from an experiment conducted in a long-term microgravity experiment up to now. The test tube had a length of $356 \mathrm{~mm}$ and a diameter of 10 $\mathrm{mm}^{[21]}$. Carbogal and air were used as the liquid and the gas phase, respectively. Figure 3 shows some typical flow patterns observed in partial and microgravity conditions aboard the Russian Space Station Mir, while Figure 4 shows the comparisons of the experimental

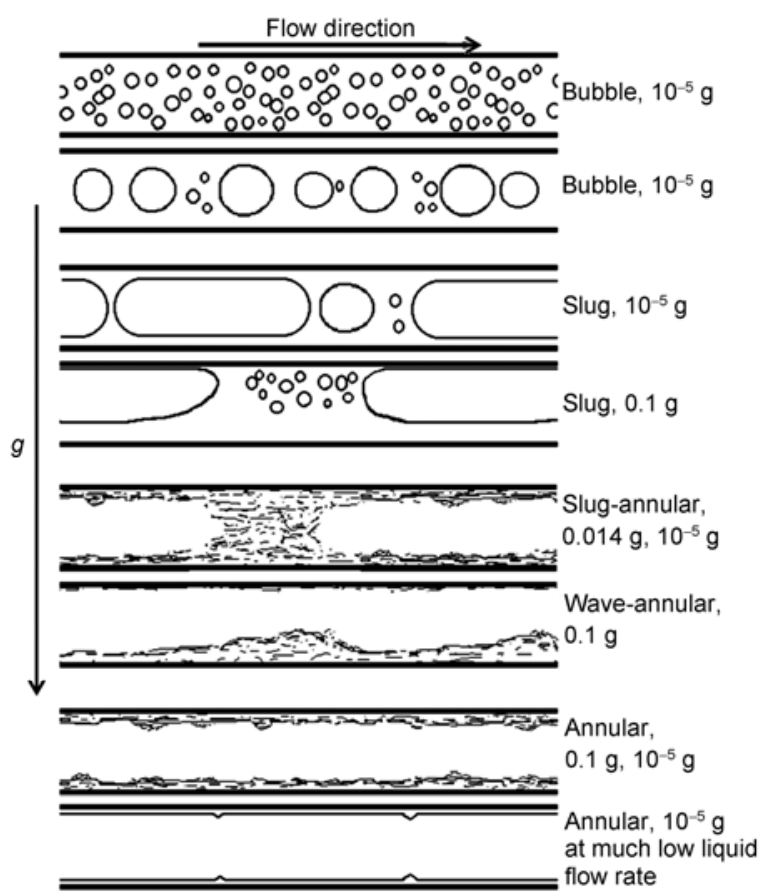

Figure 3 Typical flow patterns in different gravity conditions aboard the MIR space station.

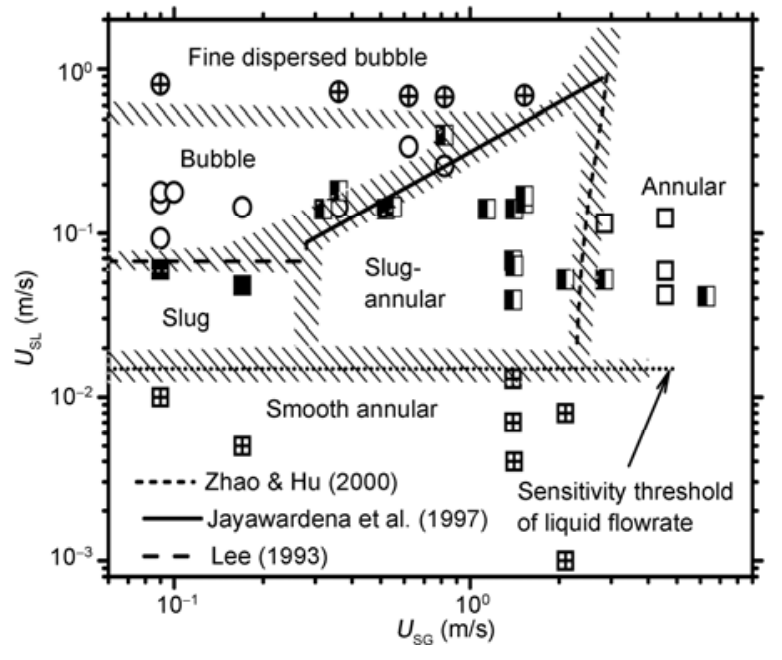

Figure 4 Flow pattern map in the microgravity condition aboard the MIR space station.

data with predictions of some commonly used models in the literature, including $\mathrm{Zhao}$ and $\mathrm{Hu}^{[22]}$, on flow pattern transition in microgravity. Some data in partial gravity conditions were also collected by rotating the experimental facility with constant speeds ${ }^{[23]}$.

A series of experiments of flow patterns and pressure drop of two-phase air-water flow through a square channel were conducted both in normal and reduced gravity aboard the Russian IL-76 reduced gravity aircraft in July 1999. The test channel had a square crosssection of $12 \mathrm{~mm} \times 12 \mathrm{~mm}$ and a length of $960 \mathrm{~mm}^{\text {[24] }}$. The influences of the gravity level and the crosssectional shape on flow pattern transition and pressure drop were studied. It was found that gravity could affect the characteristics of bubble and slug flows and the transition condition between them, but could not affect obviously the transition condition between slug and annular flows. Based on the characteristic of bubble flow in microgravity, Zhao et al. ${ }^{[25]}$ proposed that the friction factor and two-phase Reynolds number should be defined by the liquid material properties and mixture velocity of two-phase flow, and thus obtained a good correlation for the data of pressure drop in microgravity bubble flows. In the whole range of studied parameters, there were obvious differences between the experimental data of two-phase pressure drop and the predictions of the commonly used correlations in the literature. Among them, Friedel model agreed with the experimental data quite well, and then could be used to estimate pressure drop in two-phase systems for space application $^{[26]}$. 


\section{Experiment of drop Marangoni migra- tion}

Dynamic study on the drop or bubble Marangoni migration in the microgravity condition is very important, not only in theory but also in its strong background of applications. As a herald study on the phenomenon of drop or bubble Marangoni migration, the YGB model predictably presented the linear theory with excluded nonlinear convection items ${ }^{[27]}$. After that, more attentions have been paid to the study on nonlinear effects of drop or bubble migration. Currently, there are two different probabilities derived from the theories of drop migration with strong nonlinear features. Our theoretical prediction indicates that the scaled drop migration velocities $V / V_{\mathrm{YGB}}$ decrease with the increase of Marangoni number $(M a)^{[28]}$, whereas the theoretical result from Subramanian research group shows that $V / V_{\mathrm{YGB}}$ decreases at first in the smaller $M a$ region and then sharply increases with the increasing $M a$ afterward ${ }^{[29]}$. Therefore, the investigations on the behaviors of drop migration at large $M a$ in the microgravity condition provoke more attentions.

Based on the years of ground-based research of the drop or bubble migration by means of matched-density and the facility of drop shaft ${ }^{[30,31]}$, the space experiment of drop thermocapillary migration at large $M a$ was performed on board the space ship Shen Zhou (SZ-4) of China in $2002^{[32]}$. The experimental apparatus consisted of a test cell unit including drop injection system, optical diagnostics and illumination system, a recorder for data and video image recording, a controller unit and a power supply, as shown in Figure 5. During the space experiment, we successfully achieved the measurements of multi-parameters, data and image recording, experiment controllability with program control, telemetry and telecontrol. Fluorinert liquid FC-75 and 5cst silicone oil were adopted as the mediums for drop and matrix liquid phases, respectively. Accurate volume of FC-75 liquid was injected into the matrix liquid to form a preset drop size with a special dual-pipe injection technique. The migration behaviors of drops moving in matrix liquid with a set of drop diameters under different temperature gradients were observed and the migration properties and nonlinear dynamic features were attained. The space experimental results are shown in Figure 6, in which the data from space shuttle experiments and theoretical predictions ${ }^{[29]}$ are also plotted for comparison. The interference pattern of a moving drop in matrix liquid under imposed temperature gradient is given in Figure 7, showing the drop's migration wake and the temperature distribution around. The experimental results indicate that the drop size, the applied temperature gradient and the interfacial tension temperature coefficient are three significant parameters which dominate the migration velocity and are in proportion to the migration velocity in quantity. The velocity direction sensitively follows that of the temperature gradient applied. Space experimental data shows a descending proclivity that the scaled drop migration velocity $V / V_{\mathrm{YGB}}$ dwindle with the

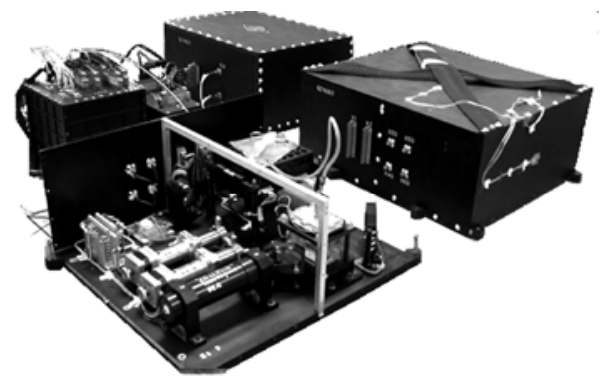

Figure 5 Space experiment apparatus.

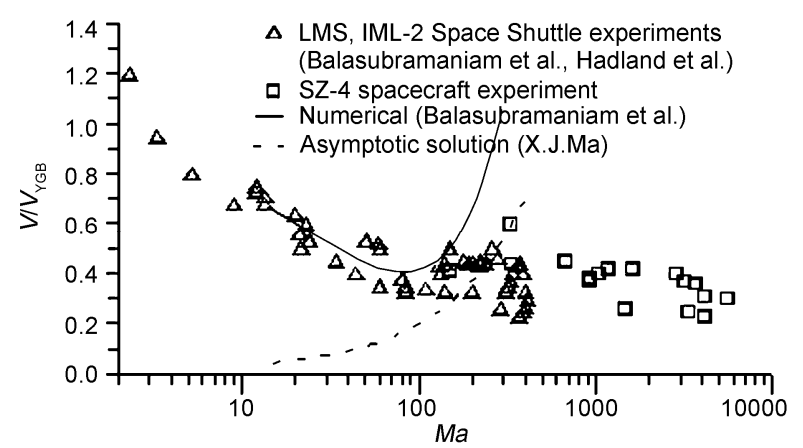

Figure 6 Scaled velocity plotted against Marangoni number; data obtained from SZ-4 space experiment, IML-2 and LMS missions. Also plotted are the predictions from asymptotic theory and numerical solution.

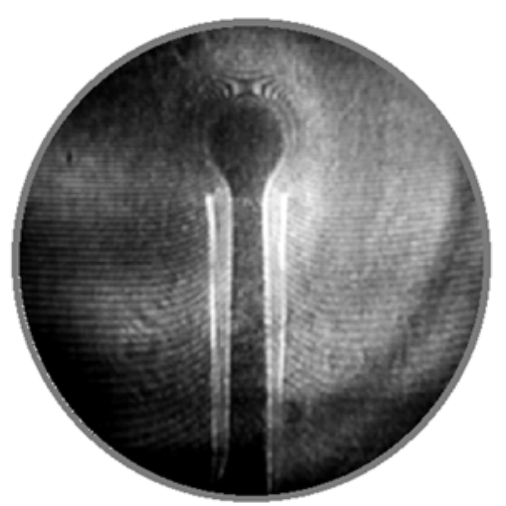

Figure 7 Interference pattern of the temperature distribution around a moving drop and its wake. 
increment of Marangoni number and the dimensionless velocity $V / V_{\mathrm{YGB}}$ gradually approaches its asymptotic value 0.4 approximately when the $M a$ number reaches up to a large value of 5500. The space experimental results agree with our theoretical predictions in general but deviates distinctly from that given by Subramanian et al.

\section{Experiment on bubbles migration and interaction}

Studies of the bubble Marangoni migration also come from linear YGB model ${ }^{[27]}$ as mentioned above. The research interests are not only limited in discipline of single bubble migration but also in the interaction between many bubbles. The research purpose is to learn the Marangoni migration of air bubble in silicon oil in previous space experiments of single bubble migration. In order to increase the Reynolds number and Marangoni number, the mediums of $50 \mathrm{cSt}^{[33]}$ and $10 \mathrm{cSt}^{[34]}$ silicon oil were used. The bubble migration experiments had been performed on board the China's 22nd recovery satellite launched in 2005 to study the interaction between dual bubbles and single bubble migration in the mean time.

The test cell of space experiment is shown in Figure 8. The test cell is composed of four optical glass walls and two aluminum blocks at the top and the bottom. KF96L $5 \mathrm{cSt}$ silicone oil was used as the continuous phase medium in the space experiment. The inner dimensions of rectangular test cavity were $70 \mathrm{~mm}$ high with the horizontal cross section of $40 \mathrm{~mm} \times 40 \mathrm{~mm}$. A piece of electric heating film and a Peltier element were respectively placed at the top and the bottom surface to establish the desired temperature gradient. In order to ensure a steady applied temperature gradient, two PID temperature controllers were used to measure and maintain constant temperatures at the top and the bottom. The temperature field of continuous phase in the test cell was measured by 4 thermocouples placed on the side wall from the top to down ward. In order to control accurately the size of injected bubbles, a cylinder and high precision Stepper-Mike actuators were used to control the injection sequence and the volume of bubbles. The whole experiment process was grabbed by a CCD camera, and the video signals were recorded in a VCR located in the recovery capsule. The maximum Marangoni number $M a$ of bubble thermocapillary migration extended from 5789 in prior space experiment to 9288 . The $R e$ and $M a$ ranged from 2.3 to 217.9 and from 98.04 to $9288^{[35]}$, respectively. The curve of the scaled velocity $V / V_{\mathrm{YGB}}$ versus $M a$ is shown in Figure 9.

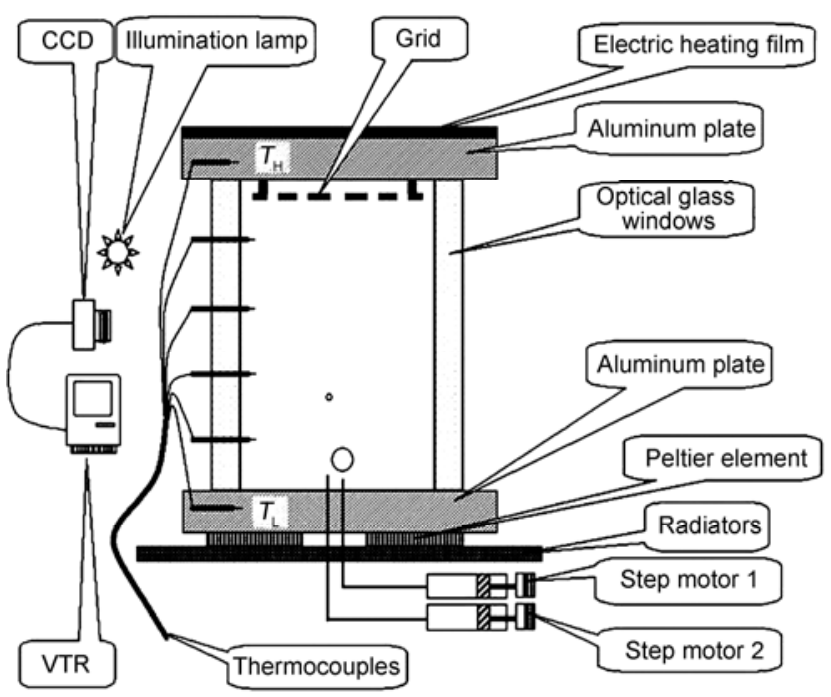

Figure 8 Schematic of the experimental apparatus.

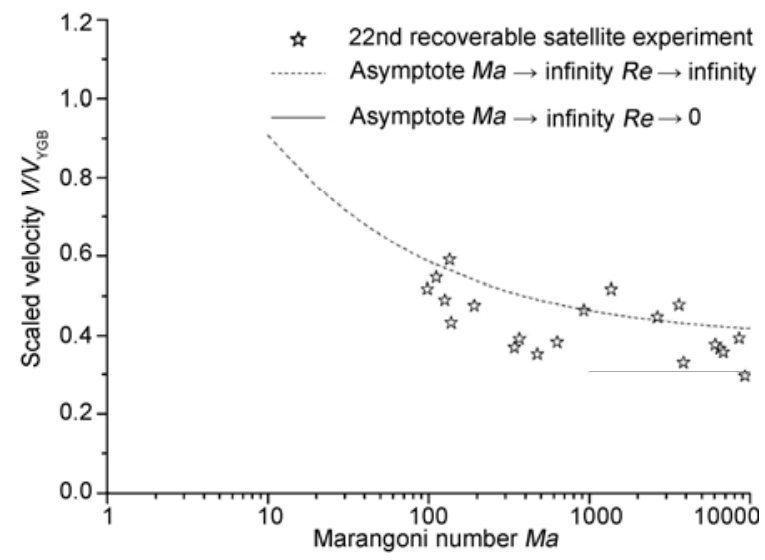

Figure 9 Scaled velocity versus $M a$.

Several groups of experiment results were obtained on bubble's interaction ${ }^{[36]}$. The variations of the vertical velocity and displacement with time are shown in Figure 10. The analysis of experiment results indicated that the velocity of smaller bubble decreased when a large bubble was migrated over it, and this effect increased when the size ratio of two bubbles was increased. The experiment data agreed with the theoretical prediction ${ }^{[37,38]}$. However, little effect on the larger bubble by the smaller could be observed when the size ratio was larger than 2 .

It is hard to observe the coalescence of the sphere bubble with larger size on the ground experiment. The process of two bubbles touch and coalescence is shown in Figure 11. Radii of two bubbles were $6.7 \mathrm{~mm}$ and 5.0 

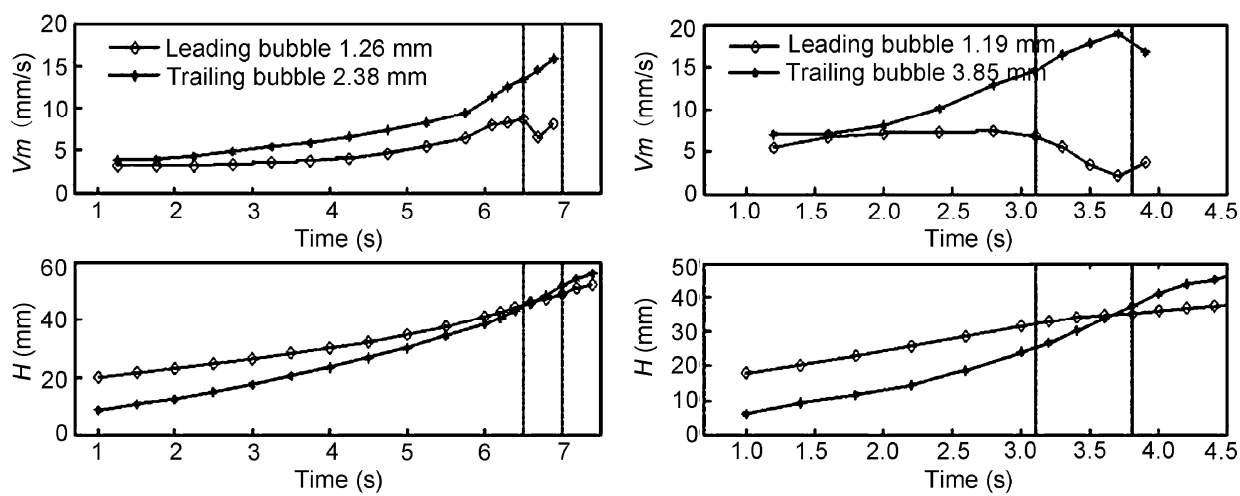

(a)

(b)

Figure 10 Location of two bubble and migration velocities versus time. (a) Size ratio $\lambda=1.89$; (b) size ratio $\lambda=3.24$.

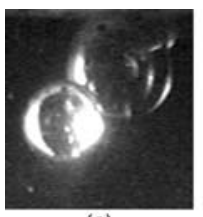

(a)

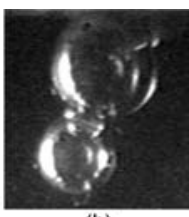

(b)

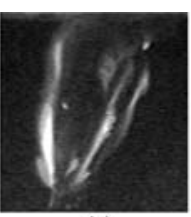

(c)

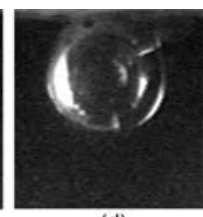

(d)
Figure 11 The process of bubble coalescence. (a) Initial position of touch $t=0 \mathrm{~s}$; (b) position of coalescence $t=22 \mathrm{~s}$; (c) instant of coalescence happening at $t=27 \mathrm{~s}$; (d) a new bubble after coalescence.

$\mathrm{mm}$, respectively. The coalescence time from touch to coalescence was $27 \mathrm{~s}$. The relationship between bubble size $r_{1}, r_{2}$ and coalescence time $t_{\text {coal }}$ were obtained based on the theoretical description of coalescence tendency related to the chemical potential difference and analysis of 19 data sets of space experiments ${ }^{[39,40]}$.

\section{Experiments on pool boiling}

Boiling phenomenon has a wide range of applications due to its high efficiency in heat transfer. In normal gravity condition, the buoyancy force can dominate the formation, growth and motions (including detaching, sliding, coalescing and oscillating) of bubbles on and near the heating surface, and thus the heat transfer from the heated wall to the liquid, which will mask the interactions among the vapor, liquid, and solid phases and the contribution of phase change, resulting in an obvious empirical characteristic of our knowledge about the mechanism of boiling heat transfer.

A space experiment was carried out aboard China's 22nd recoverable satellite (RS-22) in September 2005 $5^{[41]}$. Figure 12 shows the enhanced factor of heat transfer of nucleate pool boiling of R113 on platinum wire in microgravity. A series of experimental runs were also conducted in the Drop Tower Beijing/NMLC ${ }^{[42]}$. It was found that the heat transfer was not affected by gravity, even slightly enhanced in microgravity with no more than $10 \%$ increase of the heat flux compared with those in normal gravity. The absolute value of CHF (critical heat flux) decreased slightly in microgravity, but its scaling behavior might be predicted well by LienhardDhir model, although the value of the dimensionless radius of the heater in the present case is far beyond the initial application range of the model. The great difference between the scaling behaviors of CHF in the case of variable size with constant gravity and those in the case of variable gravity with constant size indicts that Bond number is not the sole parameter to describe the scaling behaviors of CHF in small Bond number.

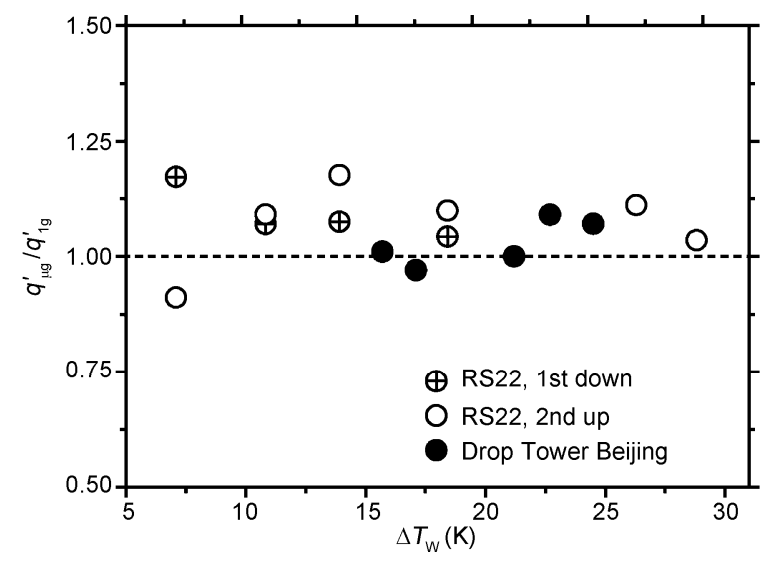

Figure 12 The enhanced factor of heat transfer in microgravity.

The bubble patterns are dramatically altered by the variation of the acceleration (Figure 13). Tiny bubbles are continually forming and growing on the surface before departing slowly from the wire when their sizes exceed the first critical value. The bigger bubbles, however, can be found staying on the surface again when their diameters are greater than the second critical value. 
If they grow further bigger than the third critical, departure will be observed again. It was also observed that the bubbles move towards the heater in space experiment. No model commonly used in the literature can predict the whole observation. The reason may be that Marangoni effect was neglected in almost all models. A new model was then proposed ${ }^{[43]}$, in which all forces acted on a growing bubble, including buoyancy, surface tension, viscous drag, inertial force, pressure gradient force and Marangoni force were taken into account. Good agreement with the observation is evident (Figure 14).

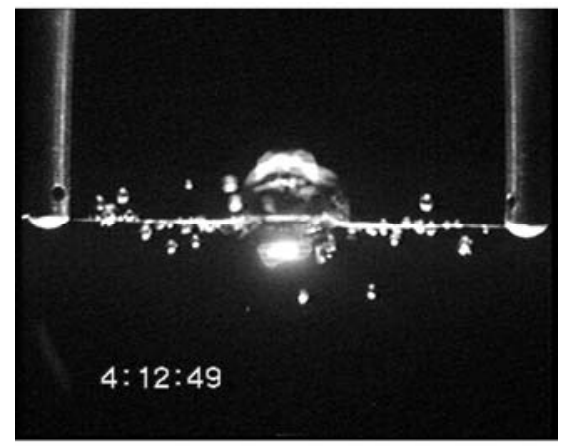

Figure 13 Bubble behavior in pool boiling on wire in long-term microgravity.

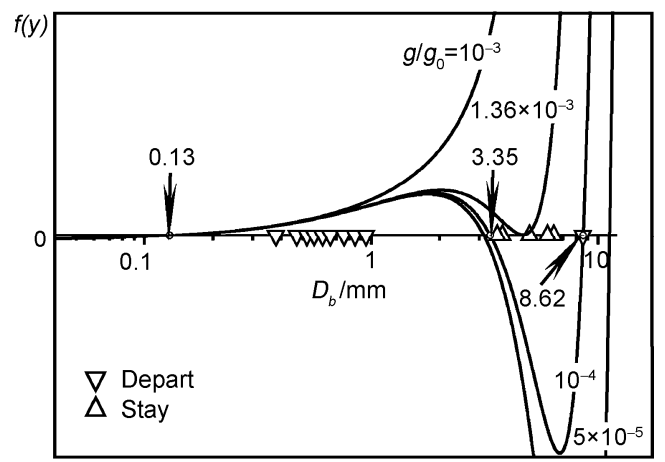

Figure 14 Force acting on a growing bubble in different gravity.

On the contrary, heat transfer on plate can be affected strongly by gravity (Figure 15). The experiment was performed aboard China's recoverable satellite SJ-8 in September, 2006. A plane plate heater was used. The working fluid was FC-72. A quasi-steady heating method was adopted, in which the heating voltage was controlled as an exponential function with time ${ }^{[44]}$. A continuous curve in each run was obtained, which could avoid the illegibility caused by the dispersal of data points obtained using a steady heating method. Obvious enhancement of heat transfer was observed in low heat flux, while the enhancement was weakened with the

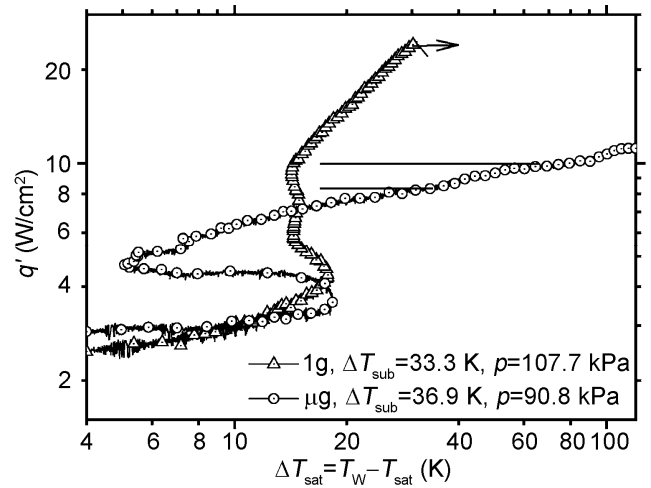

Figure 15 Boiling curves on a plate in different gravity.

increase of heat flux, and even great deterioration appeared in high heat flux. Furthermore, bubble behaviors had direct effect on the characteristic of heat transfer ${ }^{[45]}$.

\section{Experiment of liquid/liquid diffusion mass transfer}

The mass transfer process purely induced by difference of component concentration can be studied, and the diffusion coefficients can be measured precisely. Many diffusion coefficients of binary solutions have been measured and studied ${ }^{[46-49]}$. Among the related microgravity experiments, one was the space flight experiment "The Dynamics of Miscible Interfaces: A Space Flight Experiment", which was financed by NASA. Another was "Diffusion and Soret Coefficients Measurement for Improvement of Oil Recovery" belonged to "Microgravity application promotion" financed by ESA. The mass transfer processes had not been observed in real time in these two researches, and they had been measured by analyzing the liquid components after the space experiments. Rashidnia et al. ${ }^{[50]}$ designed a set of common-path interferometer, and some experiment results in normal gravity were obtained. The microgravity research center of Germany designed a two-wavelength Mach-Zehnder interferometer for the International Space Station (ISS). We developed a Mach-Zehnder interferometer to observe and measure the mass transfer processes during the crystal growth on ground experiments ${ }^{[51-55]}$. The mass transfer process of a water droplet in EAFP protein solution under microgravity condition provided by the SJ-8 satellite was monitored for the first time by a specially designed Mach-Zehnder interferometer.

The facility on board the SJ-8 satellite was composed of four substantive parts, namely the Mach-Zehnder in- 
terferometer, the image capturing system, the optical cells for holding diffusion liquid samples and the operation controlling system. The whole specially designed interferometer system had stood the serious test during the rocket launching and in the space environment. Diffusion process of a water droplet immersed in EAFP protein solution with concentration of $10 \mathrm{mg} / \mathrm{mL}$ contained in a cell with dimensions of $6 \mathrm{~mm} \times 6 \mathrm{~mm} \times 1.5 \mathrm{~mm}$ was observed. The space experiment lasted for $3.5 \mathrm{~h}$ and the results were obtained, and very clear interference fringes were obtained. Figure 16 gives a series of photos of interference fringes taken at different time, which clearly show a steady diffusion process. Figure 17 shows the whole field concentration distribution at the time of $t=1449.7 \mathrm{~s}$ calculated from the interference fringes. The results demonstrate that the mass transfer in the microgravity environment is a pure diffusion process. The concentration gradient concentrates at the water droplet region, the concentration changes smoothly and gradually far from the water droplet. Based on the analysis of the experiment data, the concentration distributions along $x$ direction, $y$ direction, and $R\left(R=\sqrt{X^{2}+Y^{2}}\right)$ direction at a fixed time are given in Figure 18. This three figures show that the mass transfers in all directions arrive at the distance of $4 \mathrm{~mm}$ to the water droplet, and the diffusion speeds are almost even. The average

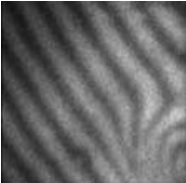

(a)

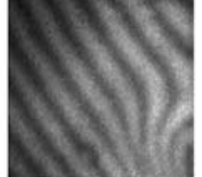

(b)

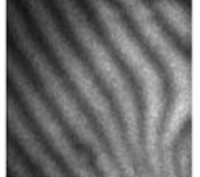

(c)

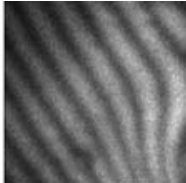

(d)
Figure 16 The interference fringes in space experiment (diffusion process). (a) $t=304.5 \mathrm{~s}$; (b) $t=548.7 \mathrm{~s}$; (c) $t=906.0 \mathrm{~s}$; (d) $t=$ $1449.7 \mathrm{~s}$.

diffusion coefficient was calculated as $2.0 \times 10^{-5} \mathrm{~mm}^{2} / \mathrm{s}$.

\section{Granular matter dynamics}

Oscillation-driven granular motions in dense (when mean free path is much less than the characteristic scale of the system) and Knudsen regimes (when mean free path is larger than the characteristic scale of the system) are recorded and studied for the first time under microgravity in SJ-8 satellite. Recent progress also included the theoretical studies on the possible transport and maneuver of granular materials in microgravity using the so called "Maxwell's demon" effect ${ }^{[54]}$.

Velocity distribution is one of the fundamental concerns in equilibrium and non-equilibrium statistical mechanics. In order to establish a suitable statistical description of granular dynamics in granular gases, the understanding of the distribution laws has been one of the research focuses in the past decade. In the SJ-8 we
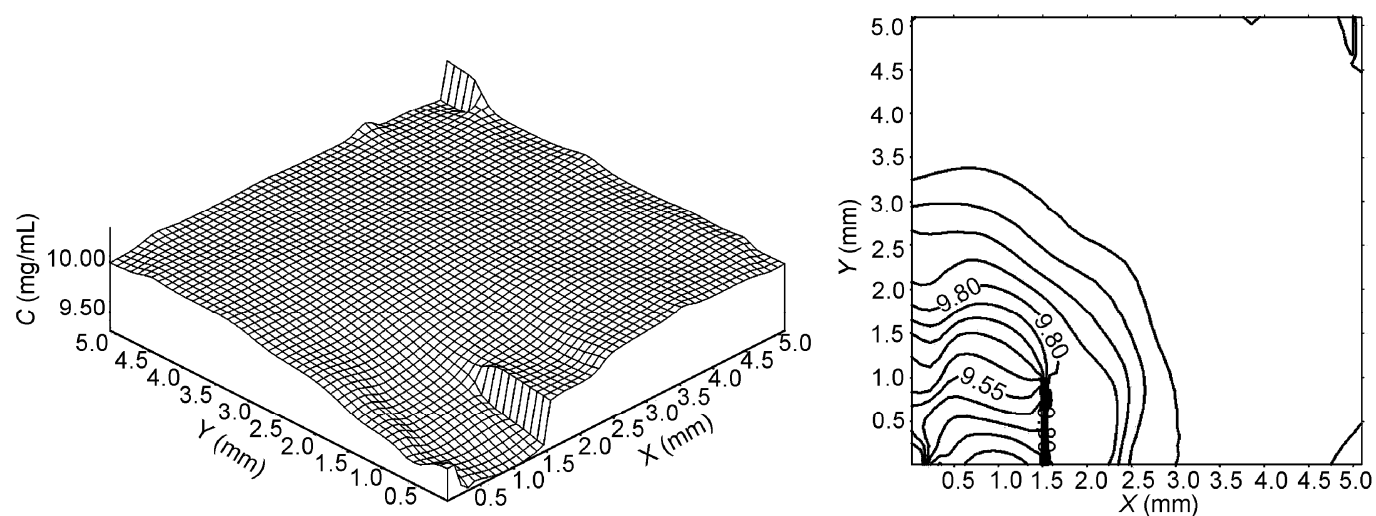

Figure 17 The concentration distribution at the time of $t=1449.7 \mathrm{~s}$.
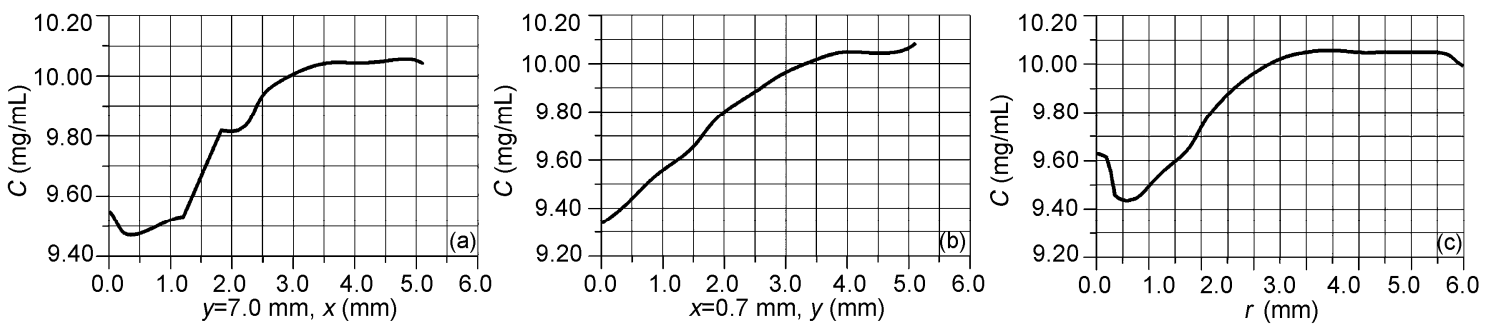

Figure 18 The concentration distribution in three directions. (a) $x$ direction; (b) $y$ direction; (c) $R$ direction. 
established a quasi-2D granular system and part of the system is shown in Figure 19. The motions of the particles were recorded in ten different vibration modes for two hours. By tracking the position of each particle in every video frame, more than 30 thousand data points of particle velocity in ten vibration modes were obtained. The velocity data of four moving particles in the cell shown in Figure 19 was analyzed and the distribution function, as shown in Figure 20, in Knudsen regime was found to be a non-Gaussian exponential decay, $\operatorname{PDF}(v)$ $\propto \exp \left\{-\left[v / v_{0}\right]\right\}$. Although non-Gaussian distribution was observed in granular gases, the transverse velocity distribution in Knudsen regime was found to be non-Gaussian and number-density dependent, indicating that finding a universal distribution law in driven granular gas systems is more complicated than one expects.

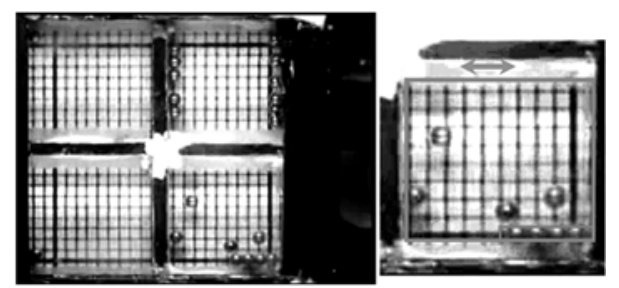

Figure 19 Cells used in SJ-8 experiment for video tracking of the particle motion.

Microgravity environment provides an essential condition for direct study of the underlining mechanism of granular behaviours such as cluster formation, nonGaussian velocity distribution and compartmentalization. The results we obtained in Knudsen regime reveal the mechanisms of density-induced gas-liquid like transition in granular gases. The statistical data in velocity distribution of granular gases helps us to connect the microscopic random motion to the macroscopic group behaviour not only in granular systems but also in bio- logical or chemical systems. It tells us that the dissipative systems are multi-scale, and there exists phase transition. Further studies have been planned for phase transition in granular gas and transport of granular materials in microgravity ${ }^{[54-59]}$.

\section{Microgravity combustion experiments}

Combustion research in the microgravity environment is a vital component of microgravity science ${ }^{[60,61]}$. Groundbased facilities and numerical simulations served as the main source of previous work in microgravity combustion studies in China. Two unique space experiments ${ }^{[62,63]}$ designed and prepared by the combustion researchers at the Institute of Mechanics and the Institute of Engineering Thermophysics, CAS respectively, were carried out on board China's recoverable satellite SJ-8 in September 2006. These experiments were concerned with the smoldering characteristics of polyurethane foam and prefire characteristics of wire insulation, respectively. The experimental studies provided valuable information for the practical application and fundamental research.

Smoldering is a non-flaming mode of combustion, which occurs primarily in the interior of porous combustible materials ${ }^{[64,65]}$. It constitutes a significant fire risk both in normal gravity and in the microgravity environment of an orbiting space facility. Since the smoldering reaction is very weak and the flow velocity inside the solid fuel is relatively low, the buoyancy-induced flow can strongly influence the processes of smoldering combustion initiation, propagation and transition to flaming. Conducted on board NASA's space shuttles, previous microgravity smoldering combustion experiments ${ }^{[66-68]}$ were focused on the smolder configurations of pure opposed flow (i.e. the reaction front propagates
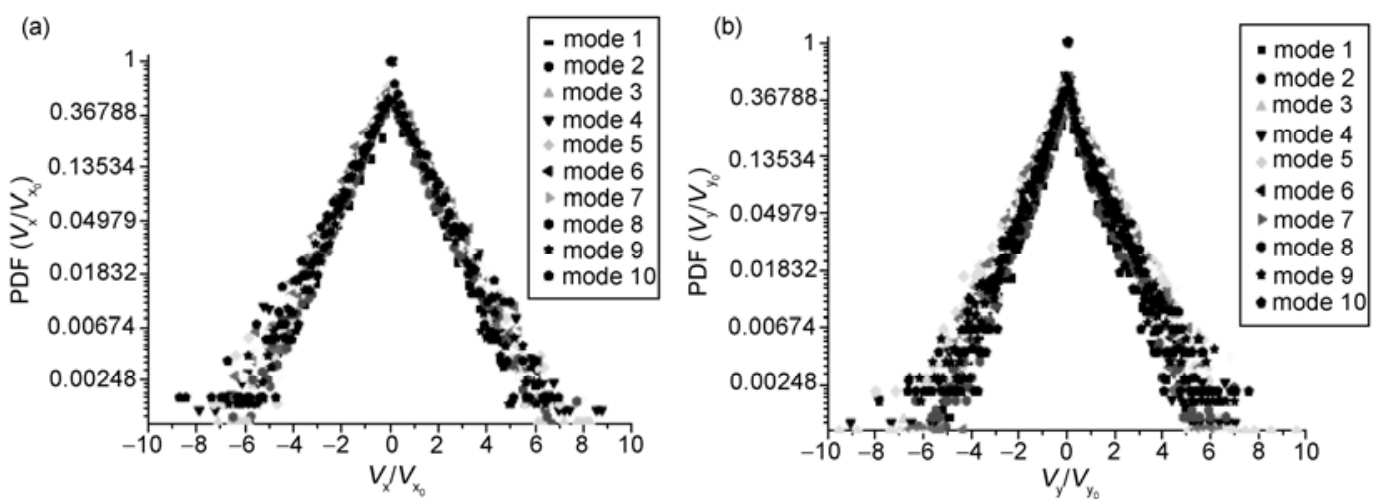

Figure 20 Statistical analysis gives the velocity distributions of $v_{x}$ and $v_{y}$ in the quasi-2D granular cell for ten vibration modes. 
opposing the oxidizer flow) or forward flow (i.e. the reaction front propagates in the same direction as oxidizer flow). Combination of these two modes has not been considered, although it is practically more important. Additionally, in these experiments ambient pressure in the test section underwent a substantial increase through the test, while the pressure effects on smoldering processes have not yet been understood. Smoldering combustion experiments on board the SJ-8 satellite were designed to investigate the smoldering mechanism of flexible polyurethane foam with central ignition in a forced flow of oxidizer ${ }^{[62]}$. This configuration resulted in a combination of opposed and forward flow smolder. The microgravity experiment is unique also in that it was performed at constant pressure (absolute value $\sim 97$ $\mathrm{kPa})$. The flight hardware of $50.5 \mathrm{~kg}$ total-weight (shown in Figure 21) included two independent experimental modules used for two tests with oxygen concentration of $21 \%$ and $35 \%$ by volume respectively. The velocity of forced oxidizer flow was $3.1 \mathrm{~mm} / \mathrm{s}$ in both tests. The results showed that in the $21 \% \mathrm{O}_{2}$ case, the microgravity opposed flow smolder reaction was not strong enough to progress through the foam sample and eventually extinguished, whereas the forward smolder propagated along the entire sample length. In the $35 \%$ $\mathrm{O}_{2}$ case, both types of smolder reactions exhibited a self-sustained propagation. As shown by the measured temperature histories in Figure 22, there was a transition from smoldering to flaming near the sample end in the opposed smolder, and it seemed to be caused by the strong acceleration of smoldering reaction. This transition served to initiate a vigorous, forward-propagating, oxidation reaction in the char left behind by the smolder reaction. The secondary char oxidation reaction propagated through the sample and consumed most of the

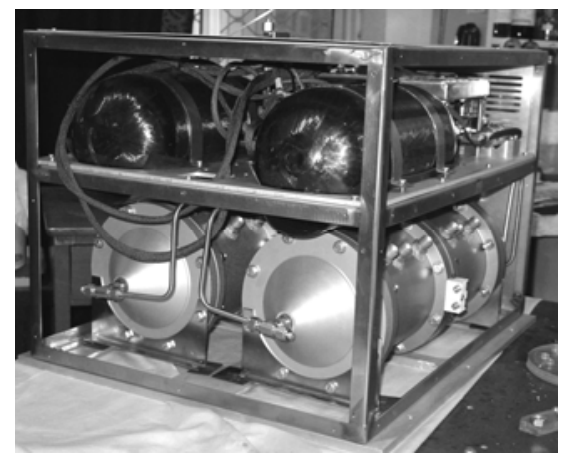

Figure 21 Flight assembly of smoldering combustion experiments onboard Satellite SJ-8 (photographed before panels fitted).

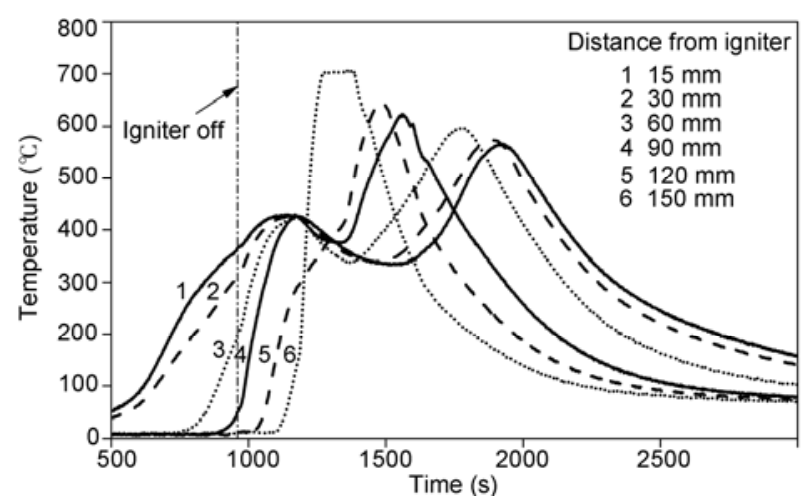

Figure 22 Temperature histories at several locations along the foam sample for the opposed flow smolder (oxygen concentration $35 \%)$.

remaining char. The data obtained in microgravity experiments can be used for the verification and development of smolder theory. At the same time, the study provides additional information of practical interest in fire safety for manned spacecraft.

The overheating and subsequent burning of wire insulation is recognized as the main ignition source of fire incidents aboard manned spacecraft. Thus the study on fire initiation of wire insulation in microgravity can lead to advances in fire prevention and detection. Using the space shuttle or drop tower, some American and Japanese researchers have investigated the flame spreading over wire insulation ${ }^{[69-72]}$ in the microgravity environment. In these previous experiments, the wire was preheated and then ignited by an external igniter. The resulting data cannot be used to interpret the wire insulation damage caused by current overload in the microgravity environment. Particularly no information can be obtained from these experiments about the precursors of fire incidents. The microgravity experiments on board the SJ-8 satellite were developed to study fire precursors of wire insulations caused by overload ${ }^{[63]}$. The fire initiation characteristics of wire insulations, including the temperature and radiation characteristics, were measured in a quiescent atmosphere. The effects of overloaded currents and wire coiled states on prefire characteristics were also examined. The atmosphere pressure in the experimental module was about $59 \mathrm{kPa}$. The polytetrafluoroethylene insulated silver-gilt copper wire was used as the test sample. It was a wire cable of the astronautic grade. The standard section area of the cable was 0.2 $\mathrm{mm}^{2}$, and the thickness of cable insulation was $0.1 \mathrm{~mm}$. The experiment results indicated that, since the natural convection almost vanished and heat loss of the over- 
loaded wire decreased notably in the microgravity environment, the temperature of the wire insulation increased continually. It might cause overheating of electric components and then result in fire. So the fire risks of wire overload in the microgravity environment are much more serious than those in normal gravity. Shown in Figure 23 are the temperature histories of wire insulations with overloaded current of $10.2 \mathrm{~A}$, where the data in the microgravity environment are compared with those from low-pressure function simulation experiments at normal gravity. In Figure 24, the temperature histories of the single wire and coiled wire are plotted, showing the effects of wire bundles on fire initiation in the microgravity environment.

\section{Space bio-fluid experiment}

Under microgravity, the convection, sedimentation and

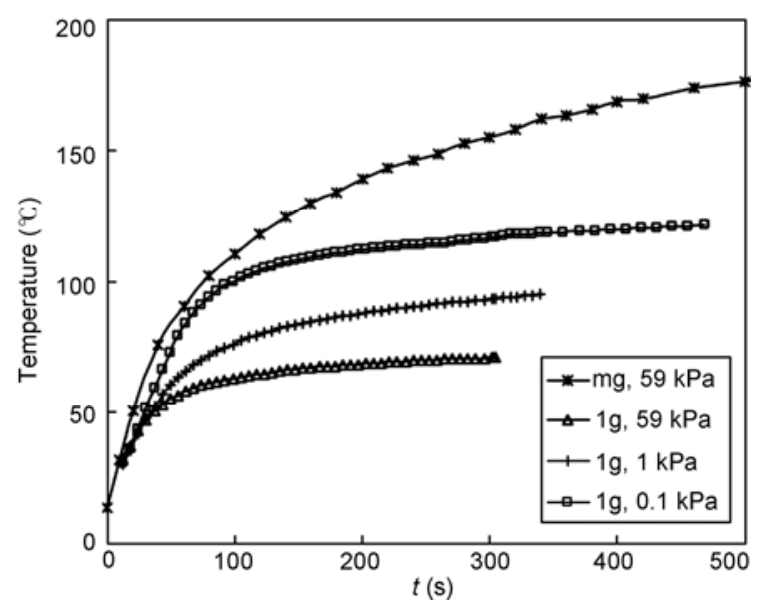

Figure 23 Temperature histories of wire insulations in micro- and normal gravity with overloaded current of $10.2 \mathrm{~A}$.

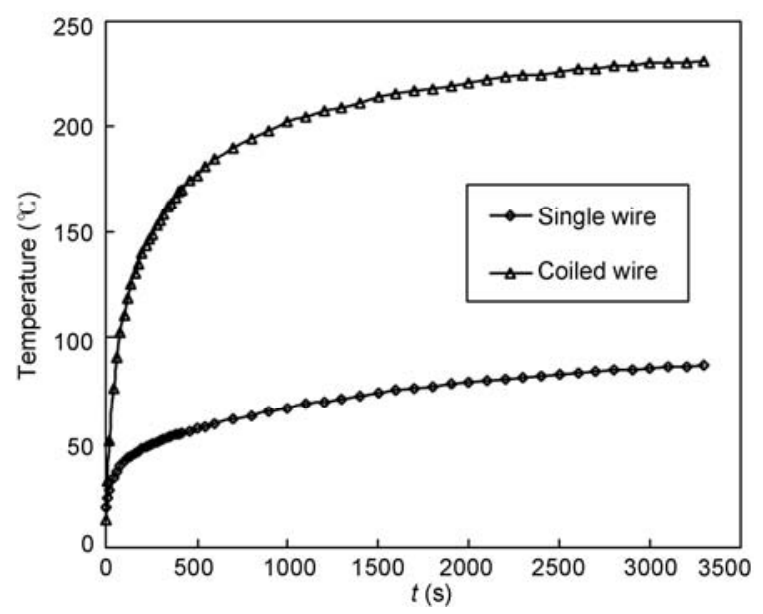

Figure 24 Temperature histories of single wire and coiled wire in microgravity. hydrostatic pressure tend to disappear and the spherical interface of gas-liquid appears randomly. Such the effects induce a significant change in mass transportation, which affects the nutrient supplies and cellular metabolism. Cells tend to death gradually due to the lack of nutrient substances when their uptake rate is higher than their diffusion rate, whereas the metabolic wastes are packed at the vicinity of the cells to generate the cytotoxic effects when the uptake rate is lower than the diffusion rate. Some cells may not be supplied with sufficient nutrient substances when the culture chamber is partially full of culture medium, while the exchanges of gas and medium in a pressurized container are hard to proceed manually in space when the medium is full. One major strategy to solve the problems is to apply the forced convection to distribute properly the nutrient substances for cells growing in space ${ }^{[73-75]}$. Since shear flow has been well known to affect the cellular responses $^{[76-78]}$, the impacts of both (micro-)gravity and shear flow are coupled together. This brings up an important issue of how the cell growth and function are regulated quantitatively under microgravity.

To address the issue, a novel concept was proposed upon a bionic phenomenon of fish gill breathing where blood flow in the arterioles that run into the filaments and lamellae is counter-directional to water flow passing the gills ${ }^{[79,80]}$. In this work, the two-way counter-directional flow and the semi-permeable membranes were used (Figure 25). Numerical simulations indicated that the impact of shear flow was negligible ${ }^{[73,74]}$ (Figure 26). Using this counter sheet-flow sandwich cell culture bioreactor, a payload experiment was conducted on the recoverable satellite launched in August 2005, where a trophoblastic tumor cell line (JAR) (ATCC, Rockville) was employed for quantifying the cellular responses as well as validating the availability of the hardware in space. The cells were recovered after 4-day on-orbit experiment and cellular glucose consumption and hormone secretion were compared with those for ground-based samples. The results indicated that the hardware was applicable to payload experiment and also made it possible to depress the negative impact of shear flow. It was also found that the glucose consumption was reduced and the hormone secretion was altered differentially for space samples as compared with those for ground-based samples. This work provided the new biomechanical rationale for uniform nutrient supply and controllable shear flow, which, in this regard, is advantageous to a 
rotating space bioreactor. The open questions include: (1) To elucidate the mechanisms from cell growth to cell differentiation, apoptosis, adhesion and aggregation as well as their molecular mechanisms under microgravity; (2) To develop the micro-fabricated pattern-based bioreactor for single cell growth and the device for on-line monitoring of cellular responses in space, and the ground-based instrument for proper simulation of microgravity effect. These future studies will be crucial to foster the cellular and tissue engineering and pharmaceutical engineering in space, to further understand the direct and indirect impacts of (micro-)gravity, and to

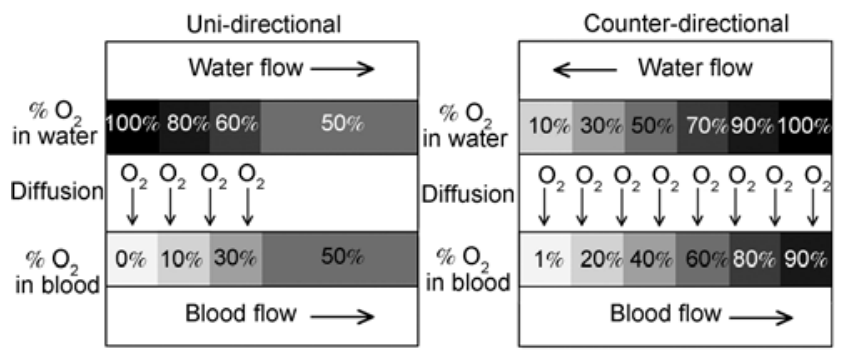

Figure 25 Biomechanical concept of a novel counter sheet-flow sandwich cell culture bioreactor. Oxygen uptake rate of blood from water stream was $50 \%$ and $80 \%$ for a uni-directional (left) and a counter-directional (right) flow, respectively ${ }^{[73,74]}$.

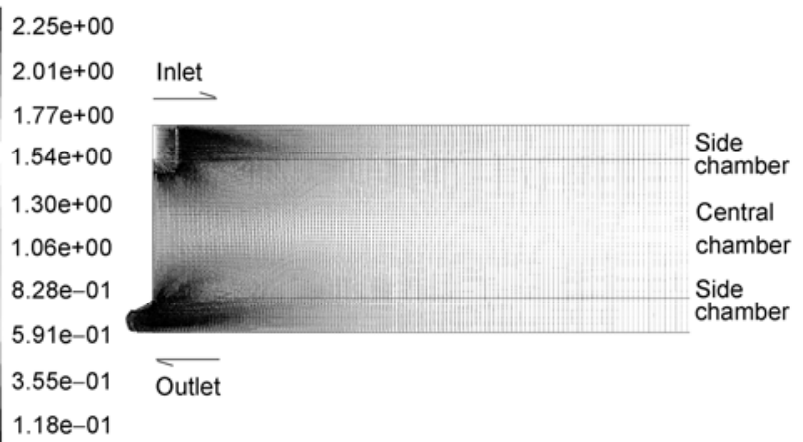

Figure 26 Distribution of shear rate at the median cross-section of the bioreactor. Plotted are the velocity vectors valued by shear rate $(1 / \mathrm{s})$. Only half of the flow field is shown upon geometric symmetry $^{[73]}$.

1 Huang H D, Chu G M, Zhan X Q. Liquid management under microgravity environment. In: $\mathrm{Hu} \mathrm{W}$ R, ed. Space Science in China. New York: Grodon \& Breach Science Publishers, 1997. 355-374

2 Lin L Y. Microgravity Science and Space Experiments in China (in Chinese). Beijing: Chinese Publisher of Science and Technology, 1988

3 Zhong X R, Lin L Y. GaAs single crystal growth in space. In: Hu W $\mathrm{R}$, ed. Space Science in China. New York: Gordon \& Breach Science Publisher, 1997. 333-354

4 Chen W C. Space materical science. In: Hu W R, ed. Space Science propose the anti-microgravity measures for astronauts via quantifying their physiological changes.

\section{Prospect}

Microgravity science is a frontier field of space science. It studies many challenging subjects with breakthrough in natural sciences, opens the application prospect for high technology development both on the ground and in space, and lays the foundation for manned explorations in the deep space. A lot of important achievements in microgravity research will be achieved with the normal operation of International Space Station. New requirements for developing microgravity science will be put forward by the National Manned Space Engineering Program, especially the Space Station Program in China. Studies of microgravity science have been gradually arranged since the late 1980s. Space experiments of microgravity science have been completed by the arrangements of the Shen Zhou space ship program and recoverable satellite program in the last decade, and have made encouraging progresses.

In the present paper, space experiment results related to fluid science in the last decade in China are summarized. In fact, a lot of theoretical and experimental researches need to be completed before the start of space experiment, and infrastructures for microgravity research have been founded gradually in China. The Chinese scientists have completed space experiments of life sciences and biotechnology, space experiments of materials science. In addition, researches on fundamental space physics are developing gradually. It can be expected that the research on microgravity science in China will have a splendid development in future, opportunities of space microgravity experiments will be increased, and the experimental resources will be more perfect. Chinese scientists will make more important contributions in the field of microgravity science.

in China. New York: Gordon \& Breach Science Publisher, 1997 $315-332$

5 Liu C X. Simulations and experiments of space biology. In: Hu W R, ed. Space Science in China. New York: Gordon \& Breach Science Publisher, 1997. 387-396

6 Bi R C. Protein crystal growth in space. In: Hu W R, ed. Space Science in China. New York: Gordon \& Breach Science Publisher, 1997. $397-414$

7 Feng M F. Cell cultivation in space. In: Hu W R, ed. Space Science in China. New York: Gordon \& Breach Science Publisher, 1997. 415- 
436

$8 \mathrm{Hu}$ W R, Xu S C. Microgravity Fluid Mechanics (in Chinese). Beijing: Science Press, 1999

9 Yao Y L, Xie J C, Shu J Z, et al. Microgravity experiment in oscillatory convection in liquid bridge of floating half zone. Acta Mech Sin, 1995, 27: 663

10 Xie J C, Lin H, Han J H, et al. Experimental investigation of thermocapillary migration of isolated drop. Adv Space Res, 1999, 24: 1409

$11 \mathrm{Hu}$ W R. Preface of special issue: Microgravity experiments on board the Chinese recoverable satellite. Microgravity Sci Tech, 2008, 20: 59

12 Birikh R V, Briskman V A, Velarde M G, et al. Liquid Interfacial Systems. New York \& Basel: Marcel Dekker, Inc., 2003

13 Schwabe D, Lamprecht R, Scharmann A. Marangoni experiment in an open boat. In: Proceedings of the Norderney Symposium on Scientific Results of the Germany Space-lab Mission D1, Norderney, Germany, 1986. 121

14 Georis Ph, Hennenberg M, Lebon G, et al. Investigation of thermocapillary convection in a three-liquid-layer system. J Fluid Mech, 1999, 389: 209-228

15 Simanovskii I B, Georis $\mathrm{Ph}$, Nepomniaschy A, et al. Oscillatory instability in multilayer system. Phys Fluids, 2003, 15: 3867

16 Liu Q S, Roux B, Velarde M G.. Thermocapillary convection in two-layer system. Int J Heat Mass Transfer, 1998, 41: 1499

17 Yao Y L, Liu Q S, Zhang P, et al. Space experiments on thermocapillary convection and Marangoni convection of two-immixible liquid layers. J Japan Soc Microgravity Appl, 1998, Suppl II: 150

18 Geng R H, Zhang P. The melting process in space experiment of fluid physics on board satellite SJ-5. Microgravity Space Station Utilization, 2000, 3: 5

19 Zhou B H, Liu Q S, Hu L, et al. Space experiments of thermocapillary convection in two-layers. Sci China Ser E, 2002, 45: 552

20 Zhao J F, Xie J C, Lin H, et al. Microgravity experiments of two-phase flow patterns aboard Mir space station. Acta Mech Sin, 2001, 17: 151

21 Zhao J F, Xie J C, Lin H, et al. Experimental studies on two-phase flow patterns aboard the Mir space station. Int J Multiphase Flow, 2001, 27: 1931

22 Zhao J F, Hu W R. Slug to annular flow transition of microgravity two-phase flow. Int J Multiphase Flow, 2000, 26: 1295-1304

23 Zhao J F, Xie J C, Lin H, et al. Gas-liquid two-phase flow patterns in partial gravity conditions (in Chinese). J Eng Thermophys, 2004, 25 : $85-87$

24 Zhao J F, Xie J C, Lin H, et al. Experimental study on two-phase gas-liquid flow patterns at normal and reduced gravity conditions. Sci China Ser E, 2004, 34: 553-560

25 Zhao J F, Xie J C, Lin H et al. Pressure drop of bubbly two-phase flow through a square channel at reduced gravity. Adv Space Res, 2002, 29: $681-686$

26 Zhao J F, Lin H, Xie J C, et al. Experimental study on pressure drop in two-phase gas-liquid flow at reduced gravity condition (in
Chinese). J Basic Sci Eng, 2001, 9: 373-380

27 Youg N O, Goldstein J S, Block M J. The motion of bubbles in a vertical temperature gradient. J Fluid Mech, 1959, 6: 350

28 Yin $\mathrm{Z} \mathrm{H}$, Gao P, Hu W R, et al. Thermocapillary migration of nondeformable drops. Phys Fluids, 2008, 20: 082101

29 Ma X J, Balasubramaniam R, Subramanian R S. Numerical simulation of thermocapillary drop motion with internal circulation. Numer Heat Transfer A, 1999, 35: 291

30 Xie J C, Lin H, Han J H, et al. Drop migration of middle Reynolds number in a vertical temperature gradient. Microgravity Sci Tech, 1996, 9: 95

31 Xie J C, Lin H, Han J H, et al. Experimental investigation on Marangoni drop migration using drop shaft facility. Int $\mathrm{J}$ Heat Mass Transfer, 1998, 41: 2077

32 Xie J C, Lin H, Zhang P, et al. Experimental investigation on thermocapillary drop migration at large Marangoni number in reduced microgravity. J Coll Interf, 2005, 285: 737

33 Balasubramaniam R, Lacy C E, Wozniak G, et al. Thermocapillary migration of bubbles and drops at moderate values of the Marangoni number in reduced gravity. Phys Fluids, 1996, 8: 872-880

34 Hadland P H, Balasubramaniam R, Wozniak G, et al. Thermocapillary migration of bubbles and drops at moderate to large Marangoni number and moderate Reynolds number in reduced gravity. Exp Fluids, 1999, 26: 240-248

35 Cui H L, Hu L, Duan L, et al. Space experimental investigation on thermocapillary migration of bubbles. Sci China Ser G, 2008, 51: 894-904

36 Kang Q, Cui H L, Hu L, et al. On-board experimental study of bubble thermocapillary migration in a recoverable satellite. Microgravity Sci Tech, 2008, 20: 67-71

37 Sun $\mathrm{R}, \mathrm{Hu} \mathrm{W}$ R. The thermocapillary migration of two bubbles in microgravity environment. J Coll Interf Sci, 2002, 255: 375-381

38 Sun R, Hu W R. Planar thermocapillary migration of two bubbles in microgravity environment. Phys Fluids A, 2003, 15: 3015-3027

39 Kang Q, Cui H L, Hu L, et al. Experimental Investigation on bubble coalescence under non-uniform temperature distribution in reduced gravity. J coll Interf Sci, 2005, 310: 546-549

40 Kang Q, Hu L, Huang C, et al. Experimental investigations on interaction of two drops by thermocapillary-buoyancy migration. Int $\mathrm{J}$ Heat Mass Transfer, 2006, 49: 2636-2641

41 Zhao J F, Wan S X, Liu G, et al. Subcooling pool boiling on thin wire in microgravity. Acta Astronautica, 2009, 64: 188-194

42 Zhao J F, Wan S X, Liu G, et al. Pool boiling heat transfer in microgravity. Microgravity Sci Tech, 2007, 19: 135-136

43 Zhao J F, Liu G, Wan S X, et al. Bubble dynamics in nucleate pool boiling on thin wires in microgravity. Microgravity Sci Tech, 2008, 20: $81-89$

44 Zhao J F, Li J, Yan N, et al. Bubble behavior and heat transfer in quasi-steady pool boiling in microgravity. Microgravity Sci Tech, 2009, 21(S1): 175-183

45 Li J, Zhao J F, Yan N, et al. Bubble behaviour in microgravity pool boiling (in Chinese). J Eng Thermophys, 2008, 29: 439-442 
46 Bowen W R, Liang Y, Williams P M. Gradient diffusion coefficients-theory and experiment. Chem Eng Soc, 2000, 55: 2359-2377

47 Laurence R, Jacques B. Influence of conformational changes on diffusion properties of bovine serum albumin: a holographic interferometry study. Coll Surf B: Biointerfaces, 2002, 25: 99-108

$48 \mathrm{He} \mathrm{C} \mathrm{H}$. Prediction of the concentration dependency of mutual diffusion coefficients in binary liquid mixtures. Ind Eng Chem Res, 1998, 34: 2148-2153

49 Yeng E, Lee Sam, Li F Y. Binary diffusion coefficients of the methanol/water system in the temperature range $30-40^{\circ} \mathrm{C}$. J Chem Eng Data, 1991, 36: 240-243

50 Rashidnia N, Balasubramaniam R. Measurement of the mass diffusivity of miscible liquids as a function of concentration using a common path shearing interferometer. Exp Fluids, 2004, 36: $619-626$

51 Duan L, Shu J Z. The convection during $\mathrm{NaClO}_{3}$ crystal growth observed by the phase shift interferometer. J Crystal Growth, 2001, 223: $181-188$

52 Kang Q, Duan L, Hu W R. Mass transfer process during the $\mathrm{NaClO}_{3}$ crystal growth process. Int J Heat Mass Transfer, 2001, 44: $3213-3222$

53 Duan L, Kang Q, Hu W R, et al. Mass transfer process and growth rate of protein crystal growth. Biophys Chem, 2002, 97: 189-201

54 Hou M, Tu H, Liu R, et al. Temperature oscillations in a compartmentalized Bi-disperse granular gas. Phys Rev Lett, 2008, 100: 068001

55 Hou M, Evesque P. Granular medium in microgravity. In: Hu W R, ed. Advances in Microgravity Sciences. Kerala, India: Research Signpost Publisher, 2008

56 Hou M, Liu R, Zhai G, et al. Velocity distribution of vibration-driven granular gas in Knudsen regime in microgravity. Microgravity Sci Tech, 2008, 20: 73

57 Hou M, Liu R, Meerson B. Gas-liquid like phase transition in granular gases under zero gravity. Chin J Space Sci, 2008, 28: 1

58 Hou M, Li Y. Probability density function of granular-gas velocity distribution (in Chinese). Chinese Sci Bull (Chinese Ver), 2009, 54: $1483-1487$

59 Liu R, Li Y, Hou M, et al. van der Waals-like phase separation instability of a driven granular gas in three dimensions. Phys Rev E, 2007, 75: 079705

60 Zhang X Q. A review on fundamental study of combustion at microgravity conditions (in Chinese). Adv Mech, 1990, 20: $83-92$

61 Zhang X. Research advances on microgravity combustion (in Chinese). Adv Mech, 2004, 34: 507-528

62 Wang S F, Zhang X. Microgravity smoldering combustion of flexible polyurethane foam with central ignition. Microgravity Sci Tech, 2008, 20: 99-105
63 Kong W, Wang B, Zhang W, et al. Study on prefire phenomena of wire insulation at microgravity. Microgravity Sci Tech, 2008, 20: $107-113$

64 Ohlemiller T J. Modeling of smoldering combustion propagation. Prog Energy Combust Sci, 1986, 11: 277-310

65 Drysdale D. An Introduction to Fire Dynamics. Chichester, England: John Wiley, 1999

66 Walther D C, Fernandez-Pello A C, Urban D L. Space shuttle based microgravity smoldering combustion experiments. Combust Flame, 1999, 116: $398-414$

67 Bar-Ilan A, Anthenien R A, Walther D C, et al. Microgravity smoldering combustion experiments in the space shuttle. AIAA Paper, 2002, 2002-1077

68 Bar-Ilan A, Rein G, Fernandez-Pello A C, et al. Forced forward smoldering experiments in microgravity. Exp Thermal Fluid Sci, 2004, 28: $743-751$

69 Greenberg P S, Sacksteder K R, Kashiwagi T. Wire insulation flammability experiment: USML-1 1 Year Post Mission Summary. NASA CP 3272, 1994

70 Greenberg P S, Sacksteder K R, Kashiwagi T. Wire insulation flammability. NASA CP 10174, 1995

71 Kikuchi M, Fujita O, Ito K, et al. Experimental study on flame spread over wire insulation in microgravity. Proc Combust Inst, 1998, 27 : $2507-2514$

72 Kikuchi M, Fujita O, Ito K, et al. Flame spread over polymeric wire insulation in microgravity. Space Forum, 2000, 6: 245-251

73 Sun S J, Gao Y X, Shu N J, et al. A novel counter sheet-flow sandwich cell culture system to unravel cellular responses in space. Microgravity Sci Tech, 2008, 20: 115-120

74 Long M, Sun S J, Huo B, et al. Biomechanics on cell responses to microgravity. In: Hu W R, ed. Advances in Microgravity Sciences. Trivandrum, India: Transworld Research Network Press, 2009, in press

75 Freed L E, Vunjak-Novakovic G. Spaceflight bioreactor studies of cells and tissues. Adv Space Biol Med, 2002, 8: 177-195

76 Mardikar S H, Niranjan K. Observations on the shear damage to different animal cells in a concentric cylinder viscometer. Biotech Bioeng, 2000, 68: 697-704

77 Wang J H, Thampatty B P. An introductory review of cell mechanobiology. Biomech Model Mechan, 2006, 5: 1-16

78 Begley C M, Kleis S J. The fluid dynamic and shear environment in the NASA/JSC rotating-wall perfused-vessel bioreactor. Biotech Bioeng, 2000, 70: 32-40

79 Piiper J, Baumgarten-Schumann D. Transport of $\mathrm{O}_{2}$ and $\mathrm{CO}_{2}$ by water and blood in gas exchange of the dogfish (Scyliorhinus stellaris). Resp Physiol, 1968, 5: 326-337

80 Hughes G M. Distribution of oxygen tension in the blood and water along the secondary lamella of the icefish gill. J Exp Biol, 1972, 56: $481-492$ 